\title{
Gerenciamento Adaptativo do SAI de Acácia Negra: uma abordagem sob a ótica da auto-organização sustentável
}

\author{
Keitiline Ramos Viacava ${ }^{1}$ e Eugenio Avila Pedrozo²
}

\begin{abstract}
Resumo: Com o surgimento do conceito de Gerenciamento Florestal Sustentável (GFS), as agroindústrias florestais vêm sendo pressionadas a tomar decisões baseadas em princípios de sustentabilidade, impulsionando todos os demais elos da cadeia à certificação. No Brasil acontece um processo que espelha este momento noSistema Agroindustrial de Acácia Negra. Isso ocorre, entretanto, em um contexto complexo, implicando decisões ambíguas e arriscadas no âmbito dos ecossistemas florestais. Assim, propõe-se a seguinte questão: quais ações estratégicas estão sendo adotadas pelos produtores florestais e como elas se relacionam com os riscos na gestão do SAI de Acácia Negra? O objetivo é analisar o processo de desenvolvimento e implementação de ações estratégicas capazes de promover ou desencorajar a auto-organização sustentável do sistema (i.e. certificação florestal). A fundamentação teórica inicia-se com uma perspectiva sistêmica orientada ao estudo das organizações e estratégias sustentáveis. Em seguida, integram-se discussões mais especificamente relacionadas às decisões, estratégias e riscos no âmbito da propriedade rural. Como metodologia incorpora-se a Post-normal science, com enfoque qualitativo. Como resultado, identifica-se que as ações estratégicas adotadas pelos produtores florestais estão dialogicamente relacionadas aos riscos, podendo exercer influências complementares, concorrentes e até antagônicas.
\end{abstract}

Palavras-chaves: Gerenciamento Florestal Sustentável, estratégias sustentáveis, unidades de manejo florestal, sistema agroindustrial, riscos, Post-normal Science.

Abstract: With the emergence of the concept of Sustainable Forest Management (SFM), forest agro-industries have been pressured to make decisions based on principles of sustainability, driving all the supply chain players toward forest certification. In Brazil, a process that mirrors this moment is happening in the Agroindustrial System of Acacia Negra. This is, however, in a complex context, implying ambiguous and risky decisions in the context of forest ecosystems. Thus, we propose the following question: what strategic

1. Doutoranda em Psicologia IP/UFRGS e mestre em Agronegócios pela UFRGS. E-mail: keitiline.viacava@ufrgs.br

2. Doutor em Administração pelo Institut National Polytechnique de Lorraine (França) e professor associado na Escola de Administração da UFRGS. E-mail: eapedrozo@ea.ufrgs.br 
actions forest producers are adopting, and how they relate to the risks in the Acacia agroindustrial system? The goal is to analyze the development and implementation of strategic actions that promote or discourage sustainable self-organization of the system (i.e. forest certification). The theoretical foundation starts with a systemic oriented perspective to the study of organizations and sustainable strategies. It integrates discussions more specifically related to the decision-making, strategies and risks within the rural property. Post-Normal science was the methodology used, following a qualitative approach. As a result, we identified that strategic actions adopted by forest producers are dialogically related to the risks and can have complementary, competitive and even antagonistic influences.

Key-words: Sustainable Forest Management, sustainable strategies, forest management units, agroindustrial system, risks, Post-Normal Science.

Classificação JEL: Q23

DOI: http://dx.doi.org/10.1590/1234-56781806-9479005301008

\section{Introdução}

A crescente demanda mundial por madeira é acompanhada por um aumento das preocupações referentes à sustentabilidade. Diante disso, a Brundtland Comission (1987) chamou a atenção para o desflorestamento e acabou exercendo influência para que o conceito de Gerenciamento Sustentável na Produção de Madeira - GSPM (Sustained Yield Timber Management - SYTM) cedesse espaço para o conceito de Gerenciamento Florestal Sustentável - GFS (Sustainable Forest Management - SFM), o qual sugere avançar na incorporação do paradigma da sustentabilidade na exploração florestal. Segundo Kant (2003, 2004), o GFS se diferencia do GSPM, pois extrapola a concepção de produção. Ele é orientado para a gestão das florestas numa perspectiva global, incluindo a preocupação com as gerações futuras e integrando os aspectos sociais e ecológicos. Em um estudo recente do mesmo autor, observa-se, porém, que a avaliação e a priorização de aspectos relevantes no GFS podem estar sujeitas ao nível de conexão que as pessoas possuem com o ambiente natural, como observado em um levantamento realizado na Tanzânia (KIJAZI e KANT, 2010).

Como decorrência desses movimentos, os compradores de produtos arborícolas passaram a exigir padrões de sustentabilidade na gestão florestal. Essa situação, aliada ao desa- fio da globalização e suas consequências - acirramento da competitividade, aumento da produtividade, necessidade de tecnologia autossustentável e redução das margens de retorno - está promovendo um processo de mudança no funcionamento das cadeias produtivas. Um exemplo desse processo pode ser observado na Bolívia (ESPINOZA e DOCKRY, 2014). Consequentemente, para se manterem competitivas, as agroindústrias florestais vêm sendo pressionadas a respeitar princípios de sustentabilidade florestal. Em face do reconhecimento da inter-relação de todas as atividades, a partir do conceito de cadeias produtivas, elas impulsionam todos os demais elos da cadeia à certificação, orientada pelos mesmos princípios (i.e. padrões Forest Stewardship Council - FSC). A tendência é que permaneçam na atividade apenas os produtores que adotem princípios sustentáveis de manejo. Convém observar, porém, que apesar de a certificação poder representar um diferencial competitivo, essa parece não ser a única razão pelas quais as organizações buscam a certificação. Um estudo que envolveu 117 países, orientado a identificar os principais motivadores para a certificação, apontou que preocupação com o meio ambiente também contribui para explicar a escolha (KOOTEN, NELSON e VERTINSKY, 2005).

No Brasil, acontece no Sistema Agroindustrial (SAI) de Acácia Negra, situada exclusivamente no estado do Rio Grande do Sul, um processo 
que espelha este momento no qual os produtores são chamados a repensar a gestão de suas unidades de manejo. Visando acelerar este processo, em 2005, um grande Grupo de Transformação Agroindustrial presente nesse segmento, iniciou o desenvolvimento de um projeto para certificação em grupo, com o objetivo de promover a mudança das práticas de manejo tradicional por práticas sustentáveis. Assim, os produtores florestais (i.e. fornecedores de matéria-prima) foram convidados a participar de três seminários/cursos e consultorias a campo. Dos produtores convidados, compareceram 20 no primeiro encontro e, por fim, restaram apenas oito. A expectativa apontada pelos organizadores do projeto era que a apreensão de informações qualificadas (i.e. exergy) acerca do processo de certificação pudesse motivar os produtores a formarem novas estruturas, neste caso a auto-organização coletiva dos mesmos, orientada para a adoção de ações estratégicas sustentáveis (i.e. Certificação em Grupo). Entretanto, as novas estruturas e estratégias que emergiram dessas interações não ocorreram como planejado.

Convém lembrar que esses processos de mudanças estão apoiados por um baixo número de estudos voltados aos Sistemas Agroindustriais (SAI) com base em produtos florestais no Brasil, especialmente no que se refere ao SAI de Acácia Negra. Juntando-se a isso as indicações de que é preciso repensar a exploração florestal numa perspectiva global, o estudo do processo adaptativo no SAI de Acácia Negra, com ênfase na produção de matéria-prima, torna-se relevante quando o uso de uma abordagem sistêmica é apresentado como alternativa. Nesse sentido, o presente estudo parte do seguinte questionamento: quais ações estratégicas estão sendo adotadas pelos produtores florestais e como elas se relacionam com os riscos na gestão do SAI de Acácia Negra? Essa discussão envolve o complexo contexto das decisões no âmbito dos ecossistemas florestais, em que o longo ciclo produtivo acaba exigindo que o estabelecimento de ações estratégicas seja realizado com anos de antecedência (aproximadamente sete anos), aumentando as incertezas e os riscos entre os objetivos e os resultados.
Este trabalho tem como objetivo analisar o processo de gerenciamento adaptativo no SAI de Acácia Negra. Nesse âmbito, em sintonia com Kay et al. (1999), trata-se especialmente dos aspectos que envolvem o processo de desenvolvimento e implementação de ações estratégicas capazes de promover ou desencorajar a auto-organização sustentável do sistema (i.e. certificação florestal). O principal motivo para a realização deste estudo surge da necessidade de se compreender o processo de tomada de decisão em um ambiente mais complexo, especialmente quando a decisão contempla a busca da sustentabilidade, envolvendo múltiplos stakeholders.

Sob essas particularidades existentes na gestão dos ecossistemas florestais, associadas à necessidade de tomada de decisão sustentável, incorpora-se ao presente estudo a metodologia denominada Post-normal science, uma ciência que atribui à decisão um papel de extrema relevância no tratamento dos problemas atuais - em que os fatos são incertos, os valores, divergentes, os riscos, altos e as decisões, urgentes (MUNDA, 2004). A partir dos apontamentos de Ravetz $(2004,2006)$, um dos precursores desta metodologia, pode-se dizer que a Post-normal science envolve o estudo dos problemas contemporâneos a partir de uma visão sistêmica, voltada à investigação de fenômenos com altas incertezas e/ou riscos. Para uma revisão histórica da Post-normal Science, ver Frame e Brown (2008). Neste estudo, a Post-normal science é operacionalizada a partir da "Metodologia para Análise dos Sistemas SOHO”, desenvolvida por Kay et al. (1999), que envolve a coleta de opiniões de diferentes stakeholders acerca da gestão de um ecossistema, apresentada na forma de narrativas.

Além desta introdução, apresenta-se uma breve revisão de literatura orientada para o entendimento da dinâmica de funcionamento dos sistemas complexos e de suas relações com as estratégias organizacionais, culminando em discussões relacionadas às decisões estratégicas no âmbito dos agronegócios. Logo após, apresentam-se os procedimentos metodológicos, seguidos da apresentação e análise dos resultados. Quanto aos resultados, cabe destacar que, ape- 
sar de compartilhar das ideias de Kay et al. (1999) acerca da interdependência existente entre governança, monitoramento e gerenciamento para o Gerenciamento Adaptativo de um Ecossistema, o presente estudo limita-se a apresentar o gerenciamento. Por último, apresentam-se as considerações finais.

\section{Estratégias sustentáveis: perspectiva sistêmica}

Muitos autores mencionam que os problemas ligados ao "Desenvolvimento Sustentável" só serão resolvidos se os aspectos socioeconômicos, culturais e ambientais forem considerados como interconectados, partes de um só sistema (e.g. GRAAF, MUSTERS e LEURS, 1996; STARIK e RANDS, 1995; SHRIVASTAVA, 1995a; GLADWIN, KENNELLY e KRAUSE, 1995). Dessas discussões emergem apontamentos acerca da importância de gestores, stakeholders e pesquisadores encontrarem um consenso de como monitorar, planejar e gerenciar esse sistema (MUNDA, 2004; KAY et al., 1999; MAYUMI e GIAMPIETRO, 2006; LEHTONEN, 2004; RAVETZ, 2004, 2006; SHRIVASTAVA, 1995b). Ao se associar essas questões às estratégias organizacionais, surge ainda a necessidade de se avançar de uma lógica predominantemente econômica para uma lógica que considere as possibilidades e consequências das estratégias em termos sistêmicos.

No entanto, esse processo não é simples e para entendê-lo alguns autores têm sugerido uma compreensão inicial das repercussões sistêmicas que compõem o funcionamento das organizações, apoiados nas contribuições de Edgar Morin (e.g. CRUZ, PEDROZO e ESTIVALETE, 2006; STAHEL, 2005). Morin (2003) conceitua a organização como "o encadeamento de relações entre componentes ou indivíduos que produz uma unidade complexa ou sistema, dotada de qualidades desconhecidas quanto aos componentes ou indivíduos" (p. 133). O autor aponta que a organização liga os elementos, acontecimentos ou indivíduos de maneira inter-relacional. A partir desse momento, eles se tornam componentes de um só sistema ou de uma unidade global. O sistema é o caráter global, ou seja, o todo. Esta unidade complexa do todo é formada por inter-relações entre esses elementos/indivíduos e o todo.

Essa mesma dinâmica organizadora ou sistêmica, característica de uma unidade complexa, também pode ser observada em uma unidade geofísica determinável, neste caso, chamada ecossistema (MORIN, 2002). Morin (2000) destaca, ainda, que a organização de um todo gera propriedades novas em relação às partes consideradas isoladamente: as emergências. Em síntese, a emergência engloba a ideia de qualidade, produto e novidade. Apesar de a lógica tradicional tender a considerar somente que o todo é maior que a soma das partes, ou seja, o ganho que surge das emergências positivas, o sistema não é somente enriquecido por essas emergências: ele também pode ser empobrecido pelas imposições. Para o autor, trabalhar numa ótica sistêmica pressupõe considerar o que nasce das interações, mesmo que estas mostrem também as perdas por imposições do sistema.

Nesta linha, é possível entender porque uma mesma estratégia organizacional pode ter repercussões distintas, possibilitando benefícios a alguns sistemas e prejuízos a outros. Portanto, as estratégias orientadas para a sustentabilidade, se consideradas como emergências (i.e. produtos das escolhas feitas nas organizações), dependem muito mais do que a simples ampliação da visão de uma organização para uma ótica sistêmica. É fundamental que a organização, ou sistema, seja vista de forma mais complexa, visto que os sistemas não são apenas enriquecidos pelas inter-relações. Eles também podem ser empobrecidos, e o empobrecimento pode ser maior que o enriquecimento, podendo ainda existir trade offs entre o empobrecimento e o enriquecimento. Deste modo, uma mesma ação estratégica (a não preservação de APP's - Áreas de Preservação Permanente, por exemplo) pode aumentar os benefícios econômicos, mas, em contrapartida, prejudicar a sustentabilidade ambiental.

Visando contribuir para o entendimento da dinâmica e funcionamento (i.e. auto-organiza- 
ção) desses sistemas, sugere-se o que Kay et al. (1999) denominaram como central para retratar as interações entre os sistemas ecológicos e humanos: a ideia de Sistema Aberto Hierárquico Autoorganizado (Self-Organizing Holarchic Open System - SOHO). Os autores destacam que o entendimento do funcionamento dos sistemas $\mathrm{SOHO}$ depende da percepção dos sistemas abertos como processos com a presença de exergy, energia, materiais ou informação de alta qualidade. Nessas circunstâncias, comportamentos coerentes aparecem nos sistemas por longos períodos de tempo, podendo mudar e até mesmo desaparecer repentinamente. Tais sistemas são organizados por atratores.

Para Kay et al. (1999), o ambiente tenderá a favorecer alguns processos. O padrão estabelecido no sistema $\mathrm{SOHO}$ pode ser classificado como um conjunto de comportamentos e propensões que são coerentemente organizados dentro da organização ou sistema, denominados atratores. Os autores salientam que alguns atratores podem ser mantidos pelo SOHO mesmo diante de pressões externas impostas pelo ambiente e destacam que os ecossistemas possuem múltiplas possibilidades de articular atratores, podendo substituir repentinamente um atrator por outro. Esta noção, contudo, é pouco explorada nos estudos ecológicos, particularmente no que se refere à gestão de recursos naturais. Outro ponto enfatizado, ao qual ainda é dada pouca relevância, diz respeito ao fenômeno de auto-organização nos sistemas humanos, a exemplo dos mercados e redes de relacionamento.

Kay et al. (1999) enfatizam ainda que os indivíduos e suas organizações também exibem as características dos sistemas SOHO. Portanto, vale lembrar que o contexto de análise pode atingir complexas escalas, além de apresentar mudanças inesperadas e não planejadas. Assim, os autores sugerem que os estudos dos sistemas humanos, na perspectiva dos sistemas $\mathrm{SOHO}$, sejam direcionados a partir dos atratores (i.e. aspirações, ambições, desejos) no intuito de reduzir as variações entre as situações percebidas e as finalidades. Em síntese, eles propõem que, a partir da inter-relação dos sistemas humanos e naturais, as pessoas possam mostrar a maneira como elas gostariam que os sistemas se desenvolvessem.

Esta visão, que tem início no entendimento da dinâmica de funcionamento dos sistemas complexos, apontando as interações existentes entre os múltiplos sistemas (MORIN, 2000, 2000, 2003) até a ideia de auto-organização, típica em sistemas abertos (KAY et al., 1999), é extremamente importante para o presente estudo. Isso ocorre porque se entende que é a partir dessa concepção integradora que surge a justificativa de esforços conjuntos (i.e. organização e stakeholders) orientados à busca de estratégias sustentáveis. A partir dessas abordagens, é possível considerar que as estratégias organizacionais, mesmo quando definidas nos limites de um ecossistema florestal (e.g. unidade de manejo florestal), estão sujeitas à compreensão das inter-relações existentes entre os produtores e seus stakeholders.

Considera-se, inclusive, que é somente a partir da disposição dessas inter-relações que todo o ecossistema agroindustrial florestal se organiza e sobrevive, ora por caminhos lineares, ora não lineares, mas podendo manter certa tendência a partir da definição de atratores compatíveis. Porém, diante dos inúmeros e complexos caminhos para análise dos indivíduos e das suas organizações, fazem-se necessárias algumas delimitações no estudo. Assim, como continuação desta revisão de literatura, parte-se dessa perspectiva sistêmica para tratar de questões mais especificamente associadas às ações estratégicas no âmbito das propriedades rurais (i.e. unidade de manejo florestal).

\section{Decisão, ação estratégica e risco na propriedade rural}

A tomada de decisão aumenta em complexidade quando analisada no âmbito dos agronegócios, especialmente no que se refere ao primeiro elo das cadeias produtivas e ao cerne dos problemas: os produtores rurais, visto que eles são geralmente prejudicados pelo baixo grau de esco- 
laridade, pela falta de infraestrutura, pelas dificuldades na gestão das unidades de produção e pela exposição aos riscos biológicos e climáticos. Para sobreviver ao contexto atual, neste caso exigente de práticas gerenciais e tecnologias sustentáveis, os produtores precisam desenvolver algumas habilidades relacionadas à tomada de decisão, de forma que seus comportamentos gerenciais estejam adequados às oportunidades e ameaças apresentadas pelo ambiente. Podem-se classificar como habilidades necessárias aos tomadores de decisão: a leitura do ambiente (i.e. a análise interna e externa à propriedade), a definição de ações estratégicas convenientes e a decisão por estruturas e tecnologias compatíveis.

Diante dessa necessidade, e aliada à escassez de modelos empíricos validados em torno do tema no período da presente revisão, neste trabalho, contribuições foram obtidas a partir de textos seminais em tomada de decisão na propriedade rural, especialmente, embora não unicamente, a partir dos trabalhos de Brossier, Chia e Petit (1990). Em resumo, os autores apresentam um "Modelo de Comportamento Adaptativo" em que a tomada de decisão é apresentada como um resultado da percepção que o agricultor e sua família possuem das finalidades e da situação. Os autores apontam ainda que o sistema agrícola é influenciado pelo ambiente externo, o que provoca ou incentiva alterações na situação. Logo, a manutenção do funcionamento do sistema agrícola depende constantemente da adaptação das finalidades da família à situação e vice-versa. Esse processo é chamado pelos autores de "dupla adaptação". Todavia, esse processo não é simples, pois envolve uma ampliação do foco de análise, o que ainda deve ser potencializado pelos produtores rurais (NANTES, 1997; RODRIGUEZ OCAÑA, 1996).

Nantes (1997) ressalta a importância do desenvolvimento da visão sistêmica do produtor rural, visto que geralmente os produtores se limitam a perceber apenas o primeiro estágio de comercialização em detrimento de analisar as demais fases presentes ao longo da cadeia produtiva. O autor salienta que passar a ver a proprie- dade não mais como uma unidade individual, mas como atuante no mercado, demanda uma série de ações como o levantamento das dificuldades existentes e dos recursos técnicos e financeiros que estão à disposição da propriedade. Somente após esse levantamento é que o produtor poderá fazer uma análise integrada de todos os elementos, formando uma estrutura que lhe permita tomar uma decisão estratégica sobre o que, quanto, como e para quem produzir.

Rodriguez Ocaña (1996) também aborda a necessidade de visualizar a exploração agrícola como um sistema. O autor divide o sistema agrícola em duas partes, interno e externo, mas que atuam como um ciclo interdependente. A esfera interna é tratada como a mais influente em relação aos critérios de gestão que, por sua vez, fornecem subsídios para as tomadas de decisão. São eles: os produtores com suas características socioeconômicas e psicológicas, as estruturas e os recursos disponíveis. Já no campo externo estão as políticas agrícolas e os fatores naturais, como o clima e os recursos da natureza propriamente ditos.

Neste momento, pode-se dizer que os produtores, quando dotados de uma visão holística, possuem a capacidade de visualizar a produção rural em sua totalidade, ou seja, têm uma visão mais abrangente da cadeia produtiva, que lhes permite tomar conhecimento não só das características da sua propriedade isoladamente, mas também das interações desta com o ambiente. Sendo assim, produtores com essa característica conseguem captar antecipadamente mudanças no ambiente, transformando-as em oportunidades, e perceber possíveis ameaças estabelecendo ações estratégicas para evitá-las ou ao menos amenizá-las. Porém, Meira e Sette (1996) alertam que pouco adianta a capacidade de visão holística do produtor e a percepção das oportunidades e ameaças do ambiente, se eles não forem criativos o suficiente a ponto de estabelecer ações estratégicas para administrar essas influências externas, estimuladoras de limitações ou de potencialidades.

Brandt (1980), em sintonia com essas questões, descreve cinco categorias de influência nas 
decisões em uma propriedade rural, especialmente em relação à escolha de uma tecnologia para produção: 1) fatores econômicos, a exemplo dos preços de produtos e insumos; 2) fatores tecnológicos, como o desenvolvimento de variedades e linhagens de alta produtividade, melhores técnicas de defesa vegetal e animal, e mecanização agrícola; 3) fatores ecológicos como precipitação, umidade do ar e temperatura; 4) fatores institucionais, relacionados com a natureza das políticas públicas no que tange a restrições ou incentivos ao comércio interno/exportações, bem como à natureza da estrutura social sob a qual se organiza o processo produtivo e 5) as incertezas, geralmente expressas na forma de expectativas.

Após o exame dessas posições, percebe-se que as decisões tomadas, influenciadas por mudanças ambientais, geram impactos no futuro das propriedades e que, geralmente, provocam alterações na organização como um todo. Já na década de 1960, Simon (1965) apontava que uma decisão pode interferir no futuro das pessoas ou das empresas de duas formas: 1) o comportamento presente, influenciado pela decisão tomada, pode limitar as possibilidades futuras e 2) as decisões tomadas no futuro podem ser guiadas em grau maior ou menor pela decisão presente. Esses elementos em conjunto dificultam o processo decisório e aumentam as incertezas e os riscos na tomada de decisão.

Sitkin e Pablo (1992) estabelecem que a definição de risco extrapola a ideia de uma característica de decisões em que exista incerteza quanto aos resultados, pois engloba também as expectativas que os indivíduos possuem e os resultados potenciais. Os autores discorrem ainda sobre o comportamento de risco, definindo-o como o grau de risco associado às decisões tomadas. Essas, por sua vez, são mais arriscadas à medida que: 1) os resultados esperados são mais incertos; 2) os objetivos são mais difíceis de atingir ou 3) o resultado potencial inclui consequências extremas. Para os autores, o comportamento de risco possui três características determinantes: preferência, percepção e propensão. A primeira envolve o gosto de arriscar e a escolha por deci- sões mais arriscadas. A segunda é definida como a avaliação dos tomadores de decisão ao risco inerente à situação. A terceira se refere à tendência do tomador de decisão a tomar ou evitar decisões de risco.

Nesse âmbito, Shimizu (2001) orienta que todos os tipos de organizações modernas vivem sob condições de riscos e incertezas, mas que estas incertezas devem ser evitadas ou, pelo menos, minimizadas por meio das seguintes ações: revisão e adaptação constante do sistema (i.e. retroalimentação ou feedback em curto prazo); adoção de decisões de dia-a-dia que não dependam de previsões futuras referentes ao ambiente externo à organização e adoção de um mecanismo de negociação com os clientes, fornecedores, concorrentes, financiadores, entre outros, mesmo que essas negociações não maximizem os ganhos em todas as transações, mas que contribuam para a redução dos riscos.

Kimura (1998) divide os fatores de riscos que geram impacto nos agronegócios em quatro grupos: de produção, operacionais, financeiros e de mercado. $\mathrm{O}$ autor alerta que tanto a propriedade rural quanto a agroindústria estão sujeitas a diversos fatores de risco que podem influenciar o resultado do negócio, visto que geralmente os riscos e os retornos dos investimentos estão inter-relacionados. Dessa forma, ele destaca que a eliminação total dos riscos pode comprometer o retorno esperado do empreendimento. Diante disso, é possível supor que o produtor rural necessite de uma atitude positiva diante desses fatores, visto que está envolvido em uma atividade cujo risco, inerente a todas as atividades produtivas, assume proporções ainda maiores se comparadas a outros segmentos. Isso porque nos agronegócios, além das influências das forças competitivas, o produtor rural está sujeito ao ciclo vital de plantas e animais e aos riscos relacionados às variáveis climáticas e biológicas.

Por último, nessa revisão, cabe destacar que modelagens mais recentes sobre tomada de decisão rural já estão disponíveis e podem apoiar estudos subsequentes. Um exemplo dessa evolução é o modelo de tomada de decisão adapta- 
tiva para política e produção rural desenvolvido por Sposito, Benke, Pelizaro e Ray Wyatt (2010). Especificamente no que diz respeito à tomada de decisão de produtores florestais, um tendência observada nesse campo é a adoção de abordagens comportamentais, orientadas a investigar de que maneira diferentes contingências ambientais afetam as escolhas dos produtores (Kant et al., 2013). A integração dessas novas abordagens podem aos poucos promover avanços no entendimento do tema.

\section{Procedimentos metodológicos}

A metodologia utilizada consiste na Postnormal science. Apesar de, conforme Tognetti (1999), essa metodologia possibilitar o estabelecimento de critérios quantitativos e qualitativos para a interpretação das constatações, optou-se por utilizar a abordagem qualitativa. A escolha da Post-normal science se justifica pela riqueza de princípios e ideias vinculadas a ela. Apesar de estar em construção, essa metodologia orienta para a busca de um equilíbrio maior entre os sistemas ecológicos e os sistemas humanos. A característica da Post-normal science que mais contribui para o presente estudo é a consideração de se investigar os fenômenos contemporâneos de forma mais complexa (TACCONI, 1998). Nesse sentido, os pesquisadores devem buscar consultar os diversos agentes envolvidos em determinados fenômenos, em uma lógica que considera como decisão sustentável aquela que culminar em um consenso entre as opiniões dos agentes envolvidos e dos pesquisadores (TOGNETTI, 1999; MAYUMI e GIAMPETRO, 2006).

Assim, entende-se que o conhecimento deve ser construído a partir da associação entre os conhecimentos científicos do pesquisador e os conhecimentos empíricos dos agentes e stakeholders envolvidos no problema a ser estudado. Deste modo, a presente pesquisa está orientada para a aplicação dos conhecimentos adquiridos através da construção coletiva de soluções para os problemas relacionados à gestão florestal, especialmente no que tange à gestão das unidades de manejo florestais de Acácia Negra no Rio Grande do Sul. A operacionalização da pesquisa é feita a partir da "Metodologia para o Estudo dos Sistemas SOHO", uma técnica desenvolvida por Kay et al. (1999), que visa auxiliar na prática das propostas ainda abstratas que envolvem a Post-normal science. A análise dos sistemas ecológicos e humanos por meio da concepção da "Capacidade de Auto-Organização dos Sistemas" (i.e. Sistemas SOHO) deve ser feita a partir de narrativas.

O ecossistema analisado consiste no SAI de Acácia Negra, localizado no estado do Rio Grande do Sul, Brasil. O foco do estudo envolve dois elos da cadeia: os produtores florestais e dois dos principais canais de transformação agroindustrial. Alguns stakeholders também foram pesquisados, como: sindicatos, consultorias, secretarias de agricultura, organizações de apoio técnico e FSC Nacional: Divisão Técnica e de Mercado. A seleção dos participantes partiu de uma amostra não probabilística do tipo intencional e envolveu dados primários e secundários. Os dados primários foram obtidos por meio das técnicas de observação direta e entrevista pessoal.

Nas propriedades florestais foram entrevistados 20 produtores já inseridos em um processo de mudança das práticas de manejo tradicional para práticas sustentáveis. Desses produtores, oito acompanharam todas as palestras e seminários do projeto de certificação, formando um grupo que se organiza em busca da certificação em grupo, codificados nesta pesquisa como (G8). Os demais produtores que não seguiram participando das palestras e seminários foram codificados como (G12). Os 20 produtores possuem, em média, 200 hectares de florestas de Acácia Negra plantados, entre terras próprias e de terceiros. Informações mais detalhadas acerca da quantidade da área plantada não serão apresentadas por solicitação dos entrevistados. Os dados secundários incluíram: contratos de parceria entre produtores e agroindústrias; material de divulgação das indústrias, especialmente o "Manual de Bom Manejo Florestal"; materiais de treinamento do programa de certificação; documentos do FSC 
apontando regras de bom manejo florestal; web sites, entre outros.

Foram realizadas 30 entrevistas com duração média de uma hora e 30 minutos. A coleta dos discursos foi feita pelos próprios pesquisadores. Em todos os casos foram utilizados questionários semiestruturados contendo questões abertas e aplicados por meio de entrevista pessoal conduzida pela técnica diretiva. As respostas foram transcritas pelos pesquisadores no momento da entrevista, com o uso de gravador em $87 \%$ das entrevistas. As entrevistas realizaram-se de outubro a dezembro de 2006. Após a aplicação dos questionários, os dados foram apresentados sob a forma de narrativas, apresentando a análise crítica dos pesquisadores ao longo das mesmas.

\section{Gerenciamento}

Esta etapa do gerenciamento adaptativo envolve, segundo Kay et al. (1999), o desenvolvimento e a implementação de estratégias para promover ou desencorajar a auto-organização no contexto de visão e planejamento comum, assim como a percepção das mudanças no contexto externo e a identificação dos feedbacks, que devem ser encorajados e desencorajados. Os autores salientam ainda que este processo envolve o gerenciamento das atividades humanas, em oposição a intervenções no sistema.

Quando os entrevistados foram questionados sobre as ações estratégicas que seriam necessárias para estimular a certificação, as respostas se concentraram na promoção de garantias por parte das agroindústrias. Entretanto, é importante ressaltar que a implementação de novas estratégias de mercado, como mecanismo para intensificar a motivação dos produtores acerca da certificação, não garante que a mesma seja obtida. A obtenção da certificação, independentemente de ser em grupo ou individual, impõe a necessidade de uma reflexão mais ampla acerca da gestão das florestas.

Brossier, Chia e Petit (1990), ao estabelecerem a ideia de dupla-adaptação de um sistema agrí- cola, indicam que a implementação da mudança engloba a percepção e a adaptação da "situação" e das "finalidades" que produtores e seus familiares possuem em relação à atividade. Assim, retoma-se a ideia desses autores para a análise do processo de adaptação da gestão das unidades de manejo florestal de Acácia Negra. Todavia, no presente estudo, evidenciam-se os aspectos relacionados à "situação".

Ponderações sobre a "situação" são feitas utilizando a abordagem de Brandt (1980) no que tange às influências na escolha por tecnologia, e a abordagem de Kimura (1998) quanto aos riscos da atividade agrícola. Brandt (1980) aponta cinco diferentes categorias de influências nas decisões em uma propriedade agrícola, especialmente em relação à escolha por determinadas tecnologias. São elas: econômicas, tecnológicas, ecológicas, institucionais e incertezas. É possível, neste estudo, identificar essas categorias e suas influências, tanto na situação atual (sem certificação), quanto na situação desejada (com certificação).

Entretanto, as percepções e ações estratégicas adotadas pelos produtores expressam inter-relações entre as cinco categorias ressaltadas por Brandt (1980) e os riscos tratados por Kimura (1998) - riscos de produção, operacionais, financeiros e de mercado. Assim, a análise dialógica das percepções e ações estratégicas adotadas pelos produtores a partir da associação das perspectivas de Brandt (1980) e Kimura (1998) reforçam a discussão. O princípio dialógico permite a identificação de elementos que, quando analisados em diferentes ângulos, neste caso curto e longo prazos, podem exercer influências complementares, concorrentes e outras vezes até antagônicas.

\subsection{Influências econômicas, institucionais e riscos associados}

A principal influência econômica está associada às questões institucionais de caráter público, como a política cambial, por exemplo. No caso específico da "situação" desejada (com certificação), produtores atentam para um incremento no risco financeiro devido ao aumento dos cus- 
tos de produção, necessários para a obtenção da certificação. Com a atividade fortemente dependente do mercado externo e a atual situação de câmbio valorizado, as agroindústrias reduzem os investimentos e, consequentemente, incorporam menos tecnologia ao segmento. Outra influência destacada é a do racionamento da atividade das empresas, em função da taxa cambial, por exemplo, que acaba reduzindo as oportunidades de negócios e/ou os preços da matéria-prima florestal. Isso reduz a renda do produtor que, por sua vez, acaba incorporando insumos de menor qualidade.

Além disso, as influências fortemente causadas por políticas cambiais, mas também fiscais (impostos cobrados ao longo da cadeia) e monetárias (taxa de juros), acabam alterando os níveis de demanda por matéria-prima florestal. De maneira geral, nos últimos anos, a situação econômica do País tem contribuído para a elevação da demanda por matéria-prima florestal. Esse fato tem estimulado produtores a adotar como ação estratégica a extração das florestas de Acácia Negra com menos de quatro anos. Ocorre que essa ação pode gerar diferentes efeitos nos riscos, quando analisada ao longo do tempo.

No curto prazo, os riscos de mercado tendem a ser menores para o produtor, pois a situação de excesso de demanda torna o mercado e os preços mais atrativos para a comercialização. Os riscos financeiros também são reduzidos, visto que as situações relacionadas à conjuntura econômica e às políticas governamentais são mais conhecidas, e o orçamento realizado para a gestão da unidade produtiva florestal pode ser beneficiado através da antecipação do retorno sobre o investimento realizado na implantação da floresta. Convém apontar que, no curto prazo, os riscos de produção e os riscos operacionais não aparecem ou não são percebidos pelos produtores.

Em contrapartida, percebe-se que, no longo prazo, essa mesma ação estratégica pode associar aspectos complementares, concorrentes e até antagônicos em relação aos percebidos no curto prazo. No longo prazo, a extração da floresta com menos de quatro anos pode aumentar os riscos de mercado e financeiros, além de associar novos riscos não percebidos no curto prazo. $\mathrm{O}$ aumento no risco de mercado pode ocorrer devido à possibilidade de desequilíbrios entre a oferta e a demanda, gerada por práticas de cortes inesperados. Acrescenta-se ainda o fato de que essas práticas, quando adotadas pela maioria, promovem a insuficiência de matéria-prima com a qualidade necessária para suprir a agroindústria. Logo, reduzem a qualidade do produto final e comprometem a competitividade das empresas, aumentando o risco de toda a cadeia produtiva.

Por conta do corte antecipado, no longo prazo é possível que haja um aumento dos riscos operacionais, ou seja, perdas de produtividade decorrentes de erros como, nesse caso, alteração no prazo de colheita. Além disso, associado ao risco operacional está o risco de produção, aquele atrelado às influências ambientais, como problemas no solo, por exemplo. A extração antecipada da floresta interrompe a reposição de nutrientes, podendo comprometer a utilização futura da terra e, consequentemente, a sustentabilidade de todo o ecossistema.

A implantação de florestas orientadas à certificação restringe a extração fora do período pré-determinado no "Plano de Manejo" - documento exigido pela certificadora. Essa adaptação ao Plano de Manejo é percebida pelos produtores como arriscada sob o ponto de vista financeiro e de mercado. Porém, ao considerar o que foi posto acerca dos riscos, pode-se dizer que a extração antecipada da floresta, apesar de representar baixos riscos financeiros e de mercado no curto prazo, gera, no longo prazo, um incremento desses mesmos riscos. Isso ocorre em função de inter-relações entre o sistema econômico e o sistema natural que, embora não percebidas ou consideradas, existem e influenciam a auto-organização do sistema.

Outro aspecto que contribui para a análise é a consideração de uma influência (neo)clássica, extremamente reducionista e imediatista. Reducionista, pois considera os riscos de mercado e financeiros e ignora os aspectos ambientais que podem interferir na produtividade futura; ime- 
diatista porque está amparada por uma ideia de maximização no curto prazo. Em contrapartida, se fosse adotada uma visão baseada na sustentabilidade, novas perspectivas de tempo e espaço seriam consideradas, o que poderia alterar a percepção dos riscos. A visão de tempo não seria apenas de curto prazo, mas incluiria o longo prazo. Do mesmo modo, o espaço não incluiria apenas inter-relações com o mercado, mas com outros sistemas, a exemplo do ambiental e do social. A partir dessas colocações, sugere-se a possibilidade de existência de influências temporais e espaciais na percepção das incertezas e riscos (perdas) e benefícios (ganhos), conforme a Figura 1.

Assim, em consonância com essas colocações, é lícito dizer que quanto mais dimensões forem agregadas na análise, aliada ainda a uma maior perspectiva temporal, mais as percepções acerca dos ganhos e perdas podem apresentar diferentes efeitos, além de se ampliarem. A Figura 1 apresenta exatamente essa ideia, ou seja, a possibilidade de que uma perda ou risco percebidos no curto prazo possam se transformar em ganho ou oportunidade quando analisados no longo prazo.

\subsection{Influências ecológicas e riscos associados}

As influências ecológicas estão relacionadas à precipitação, umidade do ar e temperatura. No que tange às influências ecológicas na escolha por tecnologia, dos aspectos ressaltados nas entrevistas o que mais contribui para o presente trabalho está relacionado à necessidade de atenção às Áreas de Preservação Permanente (APP's) para a obtenção da certificação. "Atualmente, para reduzir os custos, as florestas são implantadas sem nenhum critério de preservação das APP's. Mas, a gente percebe que os produtores que preservam mantêm seus campos mais conservados no verão" (G12d). A discussão central que envolve as APP's está relacionada à manutenção de uma distância mínima de nascentes e cursos d'água. Nesse ponto, os produtores entendem que a certificação, por aumentar os custos diretos (implantação da floresta), gerar custos indiretos (auditorias FSC) e reduzir a área para a execução da atividade florestal, acaba aumentando os riscos financeiros.

De maneira similar ao que foi mencionado anteriormente, a prática de não preservação das APP's também possui alteração nos riscos quando analisados no curto e no longo prazo. Enquanto no curto prazo o produtor pode reduzir o risco financeiro através da maximização do aproveitamento da área, no longo prazo o comprometimento das $\mathrm{APP}^{\prime}$ s prejudica a manutenção do meio ambiente e, consequentemente, gera um incremento nos riscos de produção. A influência dos aspectos ambientais sobre a produtividade da floresta pode acabar prejudicando o resultado econômico da floresta e aumentar o risco financeiro que, curiosamente, no curto prazo tende a ser controlado a partir da mesma ação. Essa ideia converge para a lógica apresentada na Figura 1.

Figura 1. Influências do tempo e do espaço na percepção de ganhos e perdas

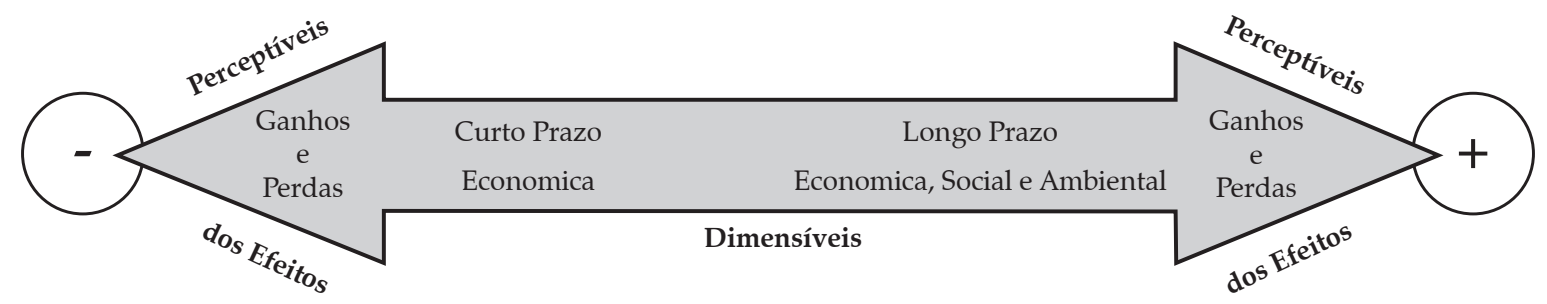

Fonte: Desenvolvido pelos autores. 


\subsection{Influências tecnológicas e} riscos associados

No que tange à escolha por tecnologia, os produtores apontam que, para obter certificação, terão que buscar uma alternativa de aumentar a produtividade a fim de tentar cobrir os custos da certificação. "O produtor tem que montar um banheiro ecológico no meio da floresta e uma casa para abrigar os trabalhadores. Isso gera custos, que devem ser compensados através de ganho de produtividade" (G8f). Nessa linha, também repensam a escolha de insumos. Para os produtores está claro que o investimento na certificação depende da escolha de insumos com maior qualidade agregada. "Os insumos devem ser melhores, para garantir certa produtividade e compensar o investimento. Foi comentado que, em seguida, o fornecedor da muda também terá que ser certificado, pois não adianta ter um elo da cadeia que não seja certificado. Quando isso acontecer, o viveirista terá que fazer novos investimentos, o que tornará a muda mais cara" (G8a).

A implantação de florestas com o uso inadequado de insumos, quando analisada no curto prazo, pode gerar uma redução do risco financeiro em função da redução do investimento realizado. Entretanto, as possibilidades de perdas decorrentes das falhas na escolha da muda ou do uso inadequado de adubo, por exemplo, podem gerar um incremento no risco operacional no longo prazo. O risco operacional é aquele oriundo de perdas provenientes de deficiências na operacionalização do processo produtivo. Logo, no longo prazo pode haver um incremento do risco financeiro, controlado no curto prazo por meio da mesma ação. Essa idea também reforça a lógica apresentada na Figura 1.

\subsection{Incertezas acerca de "ganhos" ou "perdas" para o ecossistema}

De maneira geral, a presente pesquisa evidenciou que os produtores possuem alta incer- teza com relação aos "ganhos" ou "perdas" oriundos da implantação e manutenção da certificação. As mudanças para adaptação aos princípios FSC são vistas como positivas do ponto de vista ambiental e social, mas são apontadas como negativas do ponto de vista econômico, pois o cumprimento gera a necessidade de novos investimentos e, consequentemente, o incremento dos riscos financeiros. Devido à baixa percepção relacionada à possibilidade de ganhos e perdas decorrente especialmente das limitações no acesso à informação qualificada, múltiplas percepções acerca dos efeitos das ações estratégicas são apresentadas (Quadro 1), tendo a complexidade como pano de fundo.

A partir do Quadro 1 é possível notar que uma mesma ação estratégica pode resultar em diferentes percepções por parte dos produtores e seus stakeholders no que tange às virtualidades (i.e. ganhos) e imposições (i.e. perdas) para o ecossistema florestal de Acácia Negra. Além das divergências de opiniões em termos de ganhos ou perdas, vale observar também que em alguns casos as ações estratégicas, embora percebidas pelos produtores, não são necessariamente percebidas pelos stakeholders e vice-versa.

No âmbito dessa pluralidade de opiniões acerca das ações estratégicas adotadas na gestão do ecossistema florestal de Acácia Negra, são obtidos como resultados aspectos que envolvem a complexidade. Os resultados explicitam a articulação de elementos complementares, antagônicos e similares que emergem da análise de uma mesma ação estratégica. Desse modo, salienta-se para a necessidade de uma análise mais complexa dessas escolhas - neste caso, uma análise que avalie a sustentabilidade de uma mesma ação estratégica considerando cada dimensão (i.e. social, ambiental e econômica) ora separadamente, ora conjuntamente. É possível que a partir dessa lógica se tenha uma concepção mais rica dos múltiplos aspectos que integram essas escolhas. 


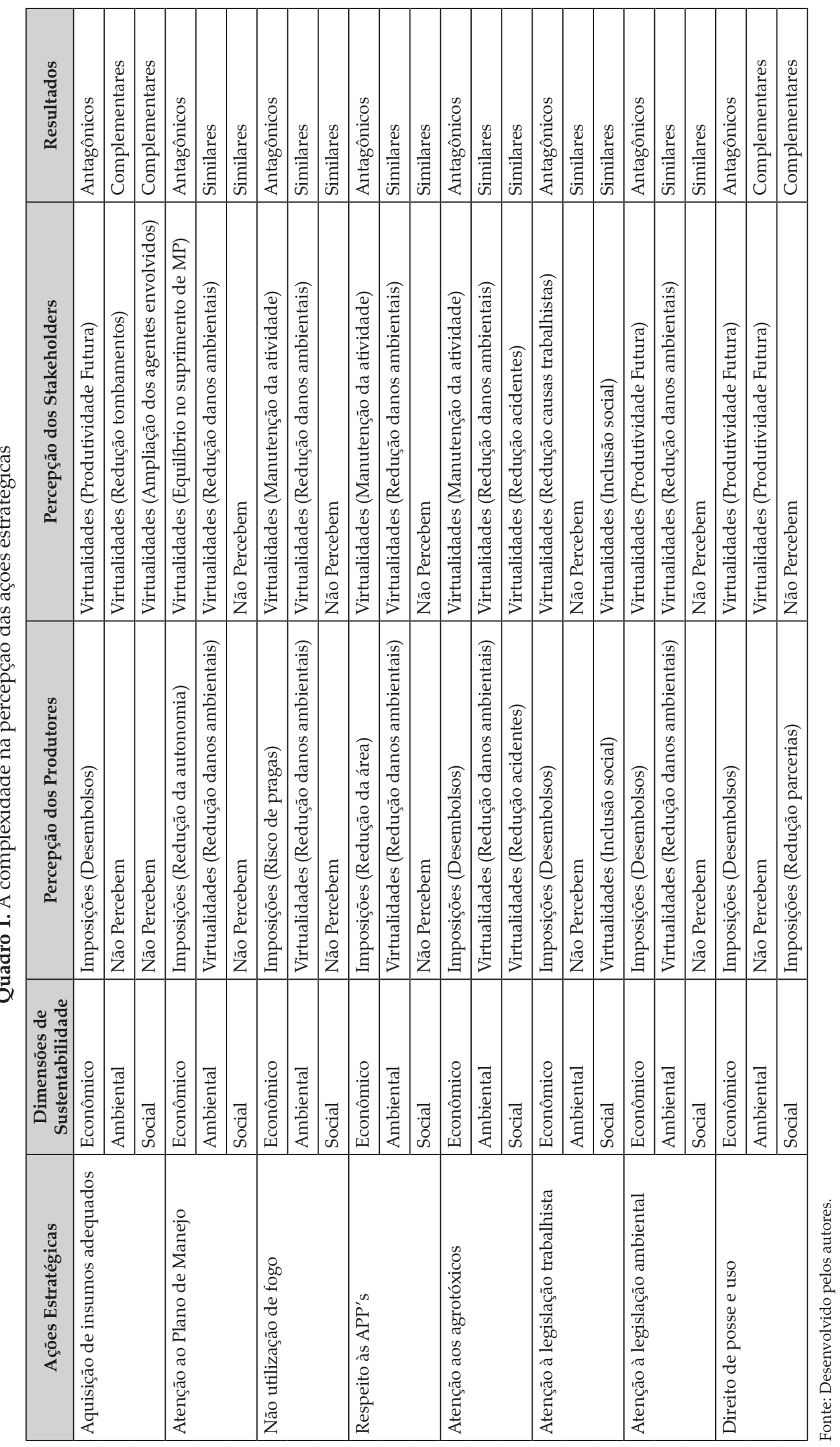




\section{Considerações finais}

Neste momento, a partir da inter-relação entre as abordagens teóricas e o tema de pesquisa, procura-se apresentar a linha de pensamento que conduziu a elaboração deste estudo.

De maneira geral, pode-se dizer que as ações estratégicas adotadas pelos produtores florestais têm ocorrido a partir da avaliação das influências econômicas, institucionais, tecnológicas, ecológicas e das incertezas, como apontado por Brandt (1980), assim como dos riscos de produção, operacionais, financeiros e de mercado, abordados por Kimura (1998). Em sintonia com os apontamentos de Rodriguez Ocaña (1996), os produtores florestais evidenciam interpretar as mudanças no contexto externo, como políticas cambiais, fatores naturais e suas influências nas condições de solo e água, além de estímulos de mercado para produtos certificados. Já na linha de Nantes (1997), buscam estabelecer escolhas sobre o que, quanto, como e para quem produzir.

Esse mecanismo de decisão é dinâmico e envolve, como tratado por Shimizu (2001), a constante revisão, retroalimentação do desempenho e adaptação do sistema. Por conta dessa dinamicidade sistêmica, à luz de Morin (2000), pode-se dizer que as ações estratégicas são, por um lado, decorrentes de inter-relações envolvendo elementos internos à unidade de manejo entre si e desses elementos com a unidade de manejo. Por outro lado, não excluindo o anterior, as ações estratégicas são oriundas de inter-relações envolvendo elementos externos à unidade de manejo entre si e desses elementos com a unidade de manejo.

Dessas inter-relações surgem alguns processos (emergências), enquanto outros são inibidos (imposições) (MORIN, 2003; KAY et al., 1999). Apesar de a lógica tradicional tender a considerar apenas os ganhos que surgem das emergências, a visão holística pressupõe a consideração das perdas causadas pelas imposições (MORIN, 2003). Desse modo, como evidenciado na presente pesquisa, é possível que a mesma ação estratégica exerça efeitos distintos, proporcionando benefí- cios à unidade de manejo e/ou prejuízos para a mesma, podendo ainda proporcionar benefícios e/ou prejuízos para outros sistemas com os quais ela interaja.

Contudo, quando as ações estratégicas pretendem a sustentabilidade, elas devem contribuir para a obtenção de um equilíbrio maior entre os múltiplos sistemas inter-relacionados, como o biológico, o econômico e o social (GLADWIN, KENNELLY e KRAUSE, 1995); no entanto, esse intercâmbio de interesses ainda é limitado (WRIGHT, KROLL e PARNELL, 2000). Os objetivos de uma organização, a exemplo do que foi evidenciado na gestão das unidades de manejo, ainda tendem a se voltar para os seus próprios valores e desejos, ignorando os demais stakeholders, como destacado por Shrivastava (1995). Em face disso, uma mudança na atuação dessas unidades de manejo florestal é necessária. Entretanto, quando analisada na sob o ponto de vista de Shrivastava (1995), essa mudança depende de uma nova orientação gerencial centralizada nos fatores tecnológicos e nos riscos, em que o contexto organizacional seja visto como um ecossistema e os riscos incluam aspectos ambientais e sociais provenientes da ação de determinadas tecnologias.

Associada a essas questões está a Post-normal science. Sua utilização como metodologia para a análise de um sistema a partir da lógica de Sistema SOHO se mostrou adequada para estudos organizacionais relacionados à tomada de decisão e estratégia. Em estudos futuros, porém, convém considerar a incorporação de princípios subsequentes apresentados na Metodologia Adaptativa para a Sustentabilidade e a Saúde de Ecossistemas (Adaptive Methodology for Ecosystem Sustainability and Health - AMESH), ver WaltnerToews e Kay (2005) para aprofundamento. A partir da lógica do sistema $\mathrm{SOHO}$, pode-se perceber que os sistemas sociais, neste caso as unidades de manejo florestal de Acácia Negra, possuem uma interação dinâmica com o seu ambiente, sejam eles fornecedores (viveiristas), clientes (agroindústrias), concorrentes (outros produtores), entidades sindicais, organizações de apoio, 
comunidades (trabalhadores), sistemas naturais (florestas), entre outros. Apesar de discordarem, os produtores de Acácia Negra não somente são influenciados pelo meio, como também exercem influência sobre ele.

As unidades de manejo podem ser vistas como sistemas dentro de outro sistema ainda maior: o SAI de Acácia Negra. As interações entre as unidades de manejo e o SAI apresentam constante interação e interdependência, orientadas para objetivos comuns (neste caso, a Certificação FSC). Entretanto, essa constatação só pode ser feita quando analisada na perspectiva do todo, pois, quando as partes são consideradas isoladamente, diferentes percepções acerca da certificação são manifestadas.

A organização do SAI, apesar de independente das unidades produtivas, está inter-relacionada a elas e vice-versa. As mudanças impostas pelo ambiente (certificação) e, consequentemente, necessárias para a manutenção da integridade do SAI (i.e. sustentabilidade econômica, social e ambiental) provocam impactos ou estímulos sobre as unidades de manejo. Esse processo, entretanto, inclui vários fenômenos não lineares. Os comportamentos dos gestores das unidades de manejo (produtores florestais) não são previsíveis, além de responderem aos estímulos impostos pelo SAI de formas distintas. Nesse contexto, inesperadas reconfigurações de um estágio de organização do sistema para outro se manifestam, como a formação do G8, por exemplo.

Na busca por um estado de equilíbrio, a organização do SAI continua incentivando a certificação, mesmo que para isso tenha que repensar seus meios, substituindo os estímulos anteriores por estímulos novos através de um processo de autoadaptação. Esse, porém, ao incluir novas variáveis no sistema, possivelmente gerará o agrupamento de novos comportamentos espontâneos e não lineares. Tais características, aliadas aos atributos naturais de um ecossistema florestal (longo ciclo produtivo $=$ decisões de longo prazo $=$ aumento de incertezas), impõem um desafio às expectativas desses gestores relacionadas a como controlar ou antecipar as mudanças nesse sistema.
Por último, por tratar-se de um sistema dinâmico, cuja sobrevivência depende em parte do suprimento de exergy, neste caso informação qualificada, sugere-se, à luz de Morin (2003), a incorporação de novas informações (i.e. informações qualificadas) no sentido de tentar ampliar as possibilidades de engajamento dos produtores florestais em programas de certificação em grupo.

\section{Referências bibliográficas}

BRANDT, S. A. Comercialização agrícola. São Paulo: Livroceres, 1980.

BROSSIER, J., CHIA, E. e PETIT, M. Modélisation systémique et système agrarie: Décision Et Oraganization. Paris: INRA, 1990.

BRUNDTLAND COMMISSION. World Commission on Environment and Development: our common future. New York: Oxford University, 1987.

CRUZ, L. B., PEDROZO, E. A. e ESTIVALETE, V. de F. B. Towards sustainable development strategies: A complex view following the contribution of Edgar Morin. Management Decision, v. 44, n. 07, p. 871-891, 2006.

ESPINOZA, O. e DOCKRY, M. J. Forest certification in Bolivia: A status report and analysis of stakeholder perspectives. Forest Products Journal, v. 64, n. 3-4, p. 80-89, 2014.

FRAME, B. e BROWN, J. Developing post-normal technologies for sustainability. Ecological Economics, v. 65, p. 225-241, 2008.

GLADWIN, T. N., KENNELLY, J. J. e KRAUSE, T-S. Shifting paradigms for sustainable development: implications for management theory and research. Academy of Management Review, v. 20, n. 04, p. 874-907, 1995.

GRAAF, H. J. de, MUSTERS, C. J. M. e LEURS, W. J. Sustainable Development: looking for new strategies. Ecological Economics, v. 16, p. 205-216, 1996.

KANT, S. Extending the boundaries of forest economics. Forest Policy and Economics, Amsterdam, v. 05, n. 1, p. 39-56, jan. 2003.

Editorial: Economics of sustainable forest management. Forest Policy and Economics, Amsterdam, v. 6, n. 3-4, p. 197-203, jun. 2004. 
KANT, S. et al. New frontiers of forest economics. Forest Policy and Economics, v. 35, 1-8, 2013.

KAY, J. J. et al. An ecosystem approach for sustainability: addressing the challenge of complexity. Futures, Guildford, v. 31, n. 07, p. 721-742, 1999.

KIJAZI, M. H. e KANT, S. Forest stakeholders' value preferences in Mount Kilimanjaro, Tanzania. Forest Policy and Economics, v. 12, p. 357-369, 2010.

KIMURA, H. Administração de riscos em empresas agropecuárias e agroindustriais. Cadernos de Pesquisas em Administração, São Paulo, v. 01, n. 07, p. 51-61, 1o tri. 1998.

KOOTEN, C. G. van, NELSON, H. W. e VERTINSKY, I. Certification of sustainable forest management practices: a global perspective on why countries certify. Forest Policy and Economics, v. 7, p. 857-867, 2005.

LEHTONEN, M. The environment-social interface of sustainable development: capabilities, social capital, institutions. Ecological Economics, Amsterdam, v. 49, n. 02, p. 199-214, jun. 2004.

MAYUMI, K. e GIAMPETRO, M. The epistemological challenge of self-modifying systems: Governance and sustainability in the post-normal science era. Ecological Economics, Amsterdam, v. 57, n. 3, p. 382-399, maio 2006.

MEIRA, J. N. e SETTE, R. de S. Sucesso econômico e perfil estrategista empreendedor de produtores rurais: o caso Nilo Coelho. In: ENCONTRO ANUAL DA ANPAD, 20., 1996, Angra dos Reis. Anais... Angra dos Reis: ANPAD, 1996. p. 85-92.

MORIN, E. O Pensamento complexo, um pensamento que pensa. In: MORIN, E. e LE MOIGNE, J-L. A Inteligência da Complexidade. 2. ed. São Paulo: Peirópolis, 2000.

. O Método II: a vida da vida. 2. ed. Porto Alegre: Sulina, 2002.

O Método I: a natureza da natureza. 2. ed. Porto Alegre: Sulina, 2003.

MUNDA, G. Social multi-criteria evaluation: Methodological foundations and operational consequences. European Journal of Operational Research, v. 158, n. 3, p. 662-677, 2004.

NANTES, J. F. D. Gerenciamento da empresa rural. In; BATALHA, M. O. (Coord.). Gestão Agroindustrial. São Paulo: Atlas, 1997, p. 489-514.
RAVETZ, J. The post-normal science of precaution. Futures, Kidlington, v. 36, n. 3, p. 347-357, apr. 2004.

. Post-Normal Science and the complexity of transitions towards sustainability. Ecological Complexity, v. 3, p. 275-284, 2006.

RODRIGUEZ OCAÑA, A. Propuesta metodológica para el análisis de la toma de decisiones de los agricultores: aplicación al caso del regadío extensivo cordobés. Córdoba/España: ETSIAM. Tesis Doctoral, 1996.

SHIMIZU, T. Decisão nas organizações: introdução aos problemas de decisão encontrados nas organizações e nos sistemas de apoio à decisão. São Paulo: Atlas, 2001.

SHRIVASTAVA, P. Ecocentric management for a risk society. Academy of Management Review, v. 20, n. 1, p. 118-137, 1995.

. The role of corporations in achieving ecological sustainability. Academy of Management Review, v. 20, n. 04, p. 936-960, 1995.

SIMON, H. A. Comportamento Administrativo: estudo dos processos decisórios nas organizações administrativas. Rio de Janeiro: Aliança para o Progresso, 1965.

SITKIN, S. B. e PABLO, A. L. Reconceptualizing the determinants of a risk behavior. Academy of Management Review, Mississipi, v. 17, n. 01, p. 9-38, jan. 1992.

SPOSITO, V. et al. Adaptation to Climate Change in Regional Australia: A Decision-Making Framework for Modelling Policy for Rural Production. Geography Compass, v. 4, n. 4, p. 335-354, 2010.

STAHEL, A. W. Value from a complex dynamic system's perspective. Ecological Economics, v. 54, p. 370-381, 2005.

STARIK, M. e RANDS, G. P. Weaving an integrated web: multilevel and multisystem perspectives of ecologically sustainable organizations. Academy of Management Review, v. 20, n. 04, p. 908-935, 1995.

TACCONI, L. Scientific methodology for ecological economics. Ecological Economics, Amsterdam, v. 27, n. 01, p. 91-105, out. 1998.

TOGNETTI, S. S. Science in a double-bind: Gregory Bateson and the origins of post-normal science. Futures, Guildford, v. 31, n. 7, p. 689-703, set. 1999.

WALTNER-TOEWS, D. e KAY, J. The Evolution of an Ecosystem Approach: the Diamond Schematic and an Adaptive Methodology for Ecosystem Sustainability and Health. Ecology and Society, v. 10, n. 01, 2005. 